\title{
A rearticulação das relações Estado-sociedade: em busca de novos significados*
}

\section{A necessidade de um referencial de análise}

Um dos sinais dos tempos atuais é o clamor, aparentemente cada vez mais consensual, pela criação de uma nova relação institucional na qual a sociedade civil cumpra papel de relevo. Entretanto, se analisarmos em profundidade os conteúcios do que parece resumir a necessidade de rearticulação das relações entre o Estado e a sociedade, constataremos que o suposto consenso tende a se esvair em variadas demandas, que vão desde a privatização quase total das atividades econômicas, e, inclusive, das políticas, até o estabelecimento de novas relações do Estado com a sociedade, baseadas na valorização da associação, no campo econômico, e no consenso, no campo político. Certamente, se há vários modelos analíticos que respaldam tais diferenças, parece igualmente certo que haja um denominador comum às diversas abordagens, que não só dificulta o esclarecimento, no plano racional-comunicativo, dos aparentes consensos e dos reais dissensos, como também pode impedir o avanço da reflexão teórica sobre o caso particular e, especialmente, sobre a própria transformação social. Tal denominador comum reside, a nosso ver, no fato de que as várias abordagens da rearticulação das relações Estado-sociedade tendem a focalizar apenas esses dois eixos da relação, sem uma perspectiva clara que oriente a transformação de ambos ou que dê sentido à reivindicação da sociedade.

Isto parece estar particularmente evidente na proposta política neo-conservadora, que fundamenta a ampliação da esfera de ação da sociedade civil basicamente na negação do Estado, dentro da institucionalidade desejável. De fato, a privatização das decisões é a conseqüência política "lógica" de se conceder ao mercado a condição exclusiva de regulador da vida econômica e política e de se considerar, com base na teoria da

Nuria Cunill Grau é Diretora do l'rograma de Documentação, Informação c Produção Editorial do Centro Latino Americano de Administração para o Desenvolvimento - CLAD

\footnotetext{
* A primcira versão deste trabalho, de março de 1994. circulou de forma limitada. Esta versão contćm modificações substanciais.
} 
eleição pública, que as autoridades políticas e os burocratas tendem a usar as instituições públicas para maximizar seu próprio bem-estar. $O$ enfoque neo-conservador, no entanto, não se caracteriza apenas por destacar a importância da sociedade civil por "default" (se deve haver menos Estado, "então" deve haver mais sociedade civil), mas por recusar a característica inerente ao Estado: a política. Como jả se verificou (LECHNer, 1981), o objetivo neo-conservador é a derrocada da política, portanto do discurso em favor da redução do papel das instituições públicas não deriva outro que fundamente a ampliação do espaço político em benefício da sociedade. Ao contrário, a "administração" da participação política, a "funcionalização-tecnificação" da participação social e a concepção da democracia como "método ou procedimento" convertem-se em expressões concretas dessa maneira particular de avaliar a instância social, que preconiza o deslocamento das decisões do Estado para a sociedade a fim não só de estabelecer controles ao governo mas, também, de desativar as demandas populares. Desmobilização e despolitização social são a contrapartida do fortalecimento da sociedade civil e da retração das instituições políticas.

Embora se vislumbre a rejeição a posições como essas, parece que se tende a manter uma abordagem instrumental da rearticulação das relações Estado-sociedade. Os sinais são certamente diferentes e podem ser expressos pela equação "Estado mais sociedade civil", no entanto os conteúdos ainda não estão fixados ou são extremamente vagos, de modo que não contribuem necessariamente para dar uma projeção diferente às relações Estado-sociedade, nem atribuem novos significados a uma ou a outra esfera. De um lado, encontra-se um forte apelo às sinergias da associação, baseada especialmente na valorização da eficiência do setor privado; de outro, constatam-se abundantes referências à necessidade da participação democrática - o que, por carecer de conteúdos claros, não designa necessariamente um princípio que fundamente o crescimento do poder da sociedade civil.

Entretanto, há também uma crescente busca de ampliação da democracia política e social como diretriz da rearticulação das relações Estado-sociedade civil. Sob esse ponto de vista, encontra-se o germe de um referencial de análise baseado na categoria "público", que este trabatho se propõe a explorar. Trata-se de uma abordagem que não pressupõe a anulação das categorias "Estado" e "sociedade", mas pretende atribuirthes novo significado, retomando o já tradicional debate sobre a autoorganização social e política da sociedade. Sob este marco teórico, que leva à indagação de novas formas e significados da democracia, coloca-se no centro do debate a aferição da igualdade, da justiça e da solidariedade, suas condições de realização em ambas as esferas (sociedade e Estado), bem como as dificuldades para sua concretização. 


\section{Desafios atuais da democratização}

A emergência de novos aspectos sociopolíticos nas realidades latinoamericanas, ligados tanto à transnacionalização da economia quanto às soluções para enfrentar a crise, bem como às heranças da cultura pósmoderna, dá o fundamento da busca de novas categorias analíticas que pretendemos realizar.

LECHNER (1986:8), ao tratar dos efeitos da cultura pós-moderna, sustenta que, na construção de um sistema político-democrático, sobressaem duas tendências: uma forte revalorização da secularização da política e o clamor ao realismo, que reapresenta a politica como "arte do possível" (em vez do necessário), e chama a atenção para o fato de que a ordem não é uma realidade objetiva, mas uma produção social, que não pode, portanto, ser obra unilateral de um ator. Ambas as tendências tentam restringir o espaço da política, anteriormente considerado excessivo. De fato, o conflito sobre os limites da politica constitui um dos terrenos privilegiados da gênese de uma nova cultura política (BoBBio, 1986). Implica, por um lado, na exigência de especificidade dos diferentes campos sociais e na aceitação da tensão existente, entre outras, entre o Estado e a política. Porém, relativiza ao mesmo tempo a centralidade do Estado, do partido e da própria politica. " $\Lambda$ ão se aceita mais a identificação do espaço político com a esfera pública. Recusa-se o enclausuramento da política, mas tampouco se aceita que tudo seja politica" (LECHNER, 1986:15).

A essa caracteristica, relacionada à crescente deslegitimação do Estado e das instituições políticas em geral, agregam-se outros fatos particularmente relevantes, que correspondem a modificações no tecido social, cujas conseqüências ainda não foram plenamente estudadas: a crescente desintegração social, expressa, entre outros, por indices de pobreza cada vez mais elevados, e a destruição de atores sociais tradicionais, provocada em grande parte pela desregulamentação e desestruturação das relações de trabalho, em consonância com a estratégia neo-liberal.'

Aliado a esses fenômenos, verifica-se o aparecimento de uma multiplicidade de novos atores socioculturais e de movimentos sociais, que, contrariamente aos do passado, com forte orientação politico-estatal, visam, em muitos casos, à conquista de identidade cultural e de espaço próprio de expressão social, politicos ou não (CALDERón \& REYNA, 1990:15). São movimentos que buscam êxito não apenas na realização dos direitos de cidadania política e social ou participação nos mecanismos da tomada de decisão, mas que também se propõem criar um espaço de conflito institucional onde possam expressar e dar vazão a suas demandas (idem: 19, 20).

Os processos de democratização enfrentam o desafio da instabilidade produzida pela indeterminacão dos limites da política e, por con- 
seguinte, o conflito relativo a eles (LECHNER, 1986:12), em um contexto caracterizado pela fragmentação da ação coletiva, pela aguda desintegração social e pela crescente concentração das decisões politicas, já não mais por parte das elites burocráticas internas, mas, principalmente e cada vez mais, por parte das elites transnacionais. Além disso, a democratização enfrenta a perda de legitimidade dos mecanismos tradicionais de fazer política, apoiados nos partidos e no parlamento, assim como o aparecimento de novos atores, que requerem uma visão nova da própria democracia.

Nesse contexto, adquirem importância central o abandono das lógicas auto-referenciais do sistema político-estatal e a luta não só pelo surgimento de um sistema politico-institucional que, além de abrigar as diferentes formas de representação social, possa reconstruir a ordem social, profundamente abalada pela crescente desintegração social, como também pela aceitação de diferentes formas de auto-expressão social. Sob diversos enfoques, esses temas estão cada vez mais presentes na agenda latino-americana pela democratização. Extremamente perceptível e recorrente é o reconhecimento da tensão crescente entre o Estado e a sociedade, que se expressa tanto na questão de que o conceito "público" (e "político") não se esgota na esfera estatal quanto na busca da preservação de identidades culturais e de maior autonomia do componente social. Junto a isso, acentua-se a consciência de que o Estado não poderá assumir os desafios de proporcionar a integração social, se não for capaz de atuar realmente como um ente público, que aposte igualmente na sua própria democratização. Nota-se, por outro lado, que se começa a questionar as estratégias de desenvolvimento centradas exclusivamente no setor estatal e/ou no privado, o que começa a legitimar a incorporação ativa da "sociedade civil" ao processo, vale dizer, confere espaço próprio às expressões de solidariedade em tais estratégias.

Em decorrência, a temática da rearticulação das relações Estadosociedade adquire outra perspectiva: o fortalecimento da sociedade civil se faz solidário com a construção da democracia e da cidadania e implica a própria democratização do Estado, ainda que não se reduza a esta. $\hat{E}$ com esses conteúdos que a categoria "público" adquire validade como instrumento de análise e marco de referência de algumas das transformações.

\section{O público, o estatal e o privado}

A introdução do conceito "público" como uma terceira dimensão, que supera a visão dicotômica que contrapõe, de maneira absoluta, o "estatal" e o "privado" está, sem dúvida, vinculada à necessidade de con- 
ferir uma amplitude diferente às relações entre o Estado e a sociedade (Portantiero, 1989:56). Segundo Lechner (1992:11,12), o público constitui um âmbito especifico, diferente da esfera politica e da esfera estatal: é tanto o espaço da deliberação coletiva dos cidadãos como a maneira pela qual a preocupação dos cidadãos com a ordem social possa atualizar o político na política.

Em termos mais amplos, a categoria analítica "público" remete a um projeto de democratização "substantiva", que afeta os aspectos econômico, social e político. Portantiero (1989:57) sustenta que as formas que essa democratização assume nos campos econômico e social é a cogestão, a autogestão, o cooperativismo que criam entre o público e o estatal um espaço de socialização, de descentralização e de autonomia nas decisões. No campo politico, implica uma forma de organização que aproxime representantes e representados, que desburocratize a gestão e a torne mais transparente e que incremente a participação do cidadão (idem: 57).

HABERMAS $(1990,1992)$, por sua vez, remete a esfera pública à recuperação de uma instância deliberativa, que faça a mediação entre o Estado e a sociedade e que ofereça àquele os fundamentos normativos oriundos das associações autônomas, que levem à democratização dos processos de formação de opinião e vontade política. ${ }^{2}$

Entretanto, apesar da difícil definição da categoria "público" e dos variados significados atribuidos a ela $\mathrm{a}^{3}$, existe um problema básico, que é invariavelmente negligenciado: a questão da organização política da sociedade como um assunto relativo a ela própria. Vários pontos desse enfoque tornaram-se objeto de discussão. Em primeiro lugar, a crítica à noção da soberania popular, segundo a qual, por intermédio do legislador soberano (o "corpo popular"), a sociedade atua sobre si mesma. ${ }^{4}$ Em segundo lugar, a reivindicação da existência de uma função pública radicada na sociedade, que, embora relevante quando a gestão dos assuntos da coletividade separou-se da sociedade para se localizar no Estado, ficando basicamente circunscrita ao âmbito privado mercantil. 5 Junto a isto, afirma-se a relatividade da esfera pública como sinônimo de Estado, sobretudo nas circunstâncias de crescente privatização das decisões públicas e de deslegitimação dos mecanismos de aferição da vontade política circunscritos a eleições mediadas por partidos políticos. De tais questões, surge a pergunta, que é: Como influir nas decisões puiblicas? Em outras palavras: Como assegurar que o Estado atue em função da sociedade?

Trata-se, é óbvio, de uma pergunta que não é nova. ${ }^{6}$ Entretanto, sua importância na atualidade se justifica, em um modelo de organização social que questiona a posição central do Estado na organização social e que assenta a reforma deste na necessidade de devolver o poder à sociedade através de processos de privatização. Tais processos, entretanto, 
podem resultar no enfraquecimento da sociedade — pelo menos, daqueles segmentos que não correspondem à sociedade mercantil - ao manter e reforçar a assimetria de poder na construção das agendas públicas, bem como ao acentuar a debilidade do Estado para as fazer cumprir. ${ }^{7}$ A representatividade, a capacidade institucional e a responsabilidade do Estado 8 tornam-se, assim, atributos cada vez mais importantes para se obter a redefinição das fronteiras entre o Estado e a sociedade e contribuir efetivamente para o fortalecimento desta última.

Os novos estudos sobre a sociedade civil reforçam essa mesma preocupação em decorrência da conscientização de que a democratização da sociedade requer a democratização e a reforma institucional da sociedade política. A transição de uma política defensiva para uma política ofensiva por parte dos movimentos sociais põe em evidência a necessidade do desenvolvimento de uma política de influência sobre o Estado para que abra o universo do discurso político a novas identidades e a normas articuladas, de maneira igualitária, na sociedade. Torna-se relevante também a adoção de uma "politica de inclusão", dirigida a obter o reconhecimento de novos atores políticos (COHEN \& ARATO, 1992).

Embora proponham caminhos diferentes, os modelos que preconizam a ampliação do espaço público tendem a convergir. De fato, se uma questão-chave é a recuperação das funções de crítica e de controle por parte da sociedade, considerando que existe um campo de tensão entre ela e o Estado, pode-se admitir que tais efeitos tornem relevantes estratégias de ação diversas, ainda que complementares. Entre elas, certamente, figura, segundo НАвERMAS (1990), o estabelecimento de condições para a formação de uma opinião pública espontânea, que, recorrendo à persuasão, possa exercer uma influência "indireta" sobre a formação da vontade politica. ${ }^{9}$ Entretanto, torna-se igualmente relevante a própria influência "direta" no aperfeiçoamento dos mecanismos de representação social e política para a elaboração das políticas e decisões públicas. Nesse sentido, não só está em jogo a otimização dos mecanismos tradicionais — eleições, partidos, formas diretas de expressão da cidadania (referendo, consulta popular etc.) — como também a possibilidade de aumentar a capacidade de a burocracia refletir a vontade pública, reacoplando-a à sociedade por meio da participação e da formação discursiva da vontade, já que é precisamente na esfera burocrática que as decisões mais importantes, que afetam a vida coletiva, são tomadas. A "participação dos cidadãos"10, inserida em uma estratégia de democratização do Estado, surge, então, como tema relevante, conexo ao estabelecimento de instâncias de mediação deliberativas (COHEN \& ARATO, 1992) e, em termos amplos, ao estabelecimento de fóruns públicos, na interface Estado, sociedade e economia, capazes de representar espaços de representação, negociação e interlocução (TELLES, 1994). 
Sob a perspectiva já enunciada, o público "no Estado" não é um dado pronto, mas um processo de construção, que supõe, por sua vez, a ativação da esfera pública social na sua tarefa de influir sobre as decisões estatais.

Existe, entretanto, outra dimensão da noção de público, que é necessário destacar. Admitindo-se que existem limites à democratização quando circunscrita ao Estado, já que definitivamente o exercício da democracia não pode ser restringido ao âmbito estatal, uma ampla literatura "l destaca a importância da democratização do processo decisório na esfera da produção e nas atividades criadoras de significado, em particular nas associadas à cultura e aos meios de comunicação. Além disso, principalmente na última década, reivindica-se a constituição de instâncias públicas de inter-relação social, formadas voluntariamente, capazes de se auto-determinarem e, portanto, independentes da mediação do Estado. Sua particularidade consiste na criação de zonas não estatais, na vida cotidiana, para a satisfação de necessidades coletivas, além das que são características dos movimentos sociais (CAPELLA, 1993).

O germe dessa instância social é o associacionismo voluntário, 12 ou seja, a realização voluntária de atividades ou a oferta de tempo, em conjunto com outros, para realizar objetivos comuns, atividades que, por terem como objetivo a sociedade, definem-se forçosamente como "públicas" e nessa categoria se inclui todo o conjunto de instituições privadas, cujos fins têm a característica de "serviço público" (FERNANDES, 1994).

A questão-chave que se ressalta é a existência de uma ação coletiva que não envolva necessariamente a afirmação de direitos ou a defesa de identidades culturais, assim como tampouco expresse a vontade de participação política com relação às instituições estatais. Trata-se de outra dimensão possivel da dimensão público: "a produção de bens públicos a partir da sociedade", baseada na solidariedade e fundamentada especialmente na necessidade de restringir a ação estatal. Entretanto, esta não é uma dimensão autônoma da primeira que foi assinalada: como já se sugeriu, torna-se cada vez mais evidente que, para que a redução do papel do Estado crie condições de fortalecimento da sociedade, deve estar assegurada no Estado a representatividade da sociedade. Portanto, pode-se afirmar que ambas dimensões convergem a um mesmo pleito: a criação de uma nova relação institucional, na qual a sociedade cumpra papel relevante.

Reivindica-se, portanto, que os interesses públicos ganhem amplitude de realização, tanto pela incorporação de maior quantidade de agentes sociais para a satisfação desses interesses, como pela criação de espaços de interlocução e negociação entre o Estado e a sociedade civil, que assegurem estarem as decisões do primeiro balizadas pela ampliação dos direitos dos cidadãos e pelas garantias à consecução desses direitos. Recriação da cidadania politica e extensão da cidadania social seriam, 
portanto, a base da problemática da construção do conceito de público. Seu horizonte: transcender a atual assimetria da representação social e politica e modificar as relações sociais em favor do incremento da autoorganização social.

\section{As novas formas de relação entre Estado e sociedade promovidas pelo próprio Estado e sua capacidade de ampliar o espaço público}

$\mathrm{Na}$ América Latina, além das reformas institucionais que se dirigem especificamente ao sistema político, em seus eixos - poder executivo, poder legislativo e partidos políticos - está em curso um conjunto de transformações nas relações Estado-sociedade, implementadas pelas instâncias governamentais, com o objetivo de mobilizar a sociedade. A natureza e o grau de tais transformações dependem fundamentalmente da matriz sociopolitica dominante em cada pais e, em particular, do papel de intermediação que os partidos políticos desempenhem, bem como da força e da capacidade de mobilização da sociedade. Entretanto, há estratégias comuns, cuja capacidade de contribuir para a construção da esfera pública, nos termos referidos, requer uma análise minuciosa para facilitar a compreensão das condições que podem aumentar sua viabilidade.

Tais transformações se associam fundamentalmente à criação de mecanismos para a participação da sociedade civil em dois processos, analiticamente passiveis de diferenciação: a manifestação de interesses de grupos sociais organizados no processo de formulação de politicas e decisões públicas e a administração privada de serviços ou programas públicos. Embora tais mecanismos não esgotem o conceito de público, remetem claramente às duas dimensões desse conceito, anotadas anteriormente: como converter o estatal em público e como assegurar, ao mesmo tempo, que a execução das tarefas públicas não se restrinja ao âmbito estatal. A demanda da sociedade parece encontrar uma resposta por parte do Estado tanto no que se refere ao estímulo à participação dos cidadãos, por ampliar os sujeitos e os meios de influência nos processos de formação da vontade política, como por favorecer a produção de bens públicos pela sociedade, segundo um modelo que sugere a complementaridade de ações entre Estado e sociedade. Em seguida, tentaremos destacar alguns dos problemas que requerem maior questionamento, em ambos os processos, com base no ponto de vista que adotamos e em um conjunto de hipóteses de trabalho. 


\section{a) A participação dos cidadãos na formulação de políticas e decisões públicas}

Associados estreitamente a processos de descentralização e em resposta a iniciativas governamentais, é possivel identificar vários esforços recentes para criar condições para que a sociedade civil e, em particular, as organizações que representam interesses coletivos assumam algumas das fases da elaboração de decisões públicas. De fato, em um trabalho de investigação prévia (CUNILL, 1991), percebemos a intensa formalização do processo de participação dos cidadãos ocorrida na América Latina, na última década, quer pelo estabelecimento de normas juridicas, quer pela adoção de procedimentos e instâncias orgânicas para tal fim. Entretanto, com exceção de alguns processos consensuais para a elaboração de políticas de controle da inflação, preços e salários, há evidências de que tais mecanismos parecem não ter obtido avanços quanto à maior participação da sociedade civil, em especial por parte dos atores não tradicionais, na formulação de políticas e decisões públicas.

Primeiramente, se constata que a tentativa mais radical, dentro de um contexto democrático, de envolver diretamente a sociedade civil organizada na "adoção" de decisões governamentais, desapareceu antes de atingir a maturidade. Com efeito, se descartarmos o impulso que o regime autoritário de Augusto Pinochet, no Chile, concedeu à participação dos cidadãos, em substituição à participação política, esta só terá sido institucionalizada nos governos regionais estabelecidos no Peru, durante a presidência de Alan Garcia, atualmente suprimidos. Um outro possível caso paradigmático seria a experiência de Villa El Salvador, onde se alcançou, segundo reconhecem os estudiosos, um elevado nivel de auto-desenvolvimento comunitário em cooperação com o exercício compartilhado do poder político. Tal modelo terminou encontrando profundas limitações por sua lógica discrepar da sociedade quanto à aplicação das atuais politicas econômicas.

Em contrapartida, é possivel exemplificar graus significativos de envolvimento da sociedade civil no governo local, embora basicamente associados a administrações municipais dominadas por partidos de orientação popular. As experiências da prefeitura de Lima, durante o governo da Esquerda Unida, foram inumeráveis. Atualmente, no Brasil, ressaltam-se as experiências do Orçamento Participativo, iniciadas em diversas prefeituras municipais, em sua maioria ocupadas por políticos filiados ao Partido dos Trabalhadores, que estimularam a criação de conselhos municipais, com representantes eleitos pela população, para escolher os principais projetos de investimento, assim como a proporção do orçamento a ser destinada a cada um deles. Trata-se, entretanto, de "práticas participativas" que, exatamente por sua grande dependência de uma correlação favorável de forças politicas, estão marcadas pela vulnerabilidade. 
Em sintese, pode-se destacar que, apesar do discurso amplamente favorável à participação dos cidadãos, esta ainda não encontrou condições propícias para seu exercício nos espaços governamentais, porque está vinculada à possibilidade de contribuir para a democratização destes. Ao contrário, pode-se sustentar mais corretamente que as próprias formas adotadas para a institucionalização da participação da sociedade civil na esfera político-estatal podem ser esclarecedoras de suas limitações, considerando-se que, em vez de facilitarem o incremento da representação social, elas podem legitimar o corporativismo da máquina estatal, limitando ainda mais a ampliação do conceito "público".

Esta hipótese decorre de admitirmos que o potencial democratizador da participação dos cidadãos esteja condicionado à possibilidade de esta vir a produzir uma alteração real nas assimetrias da representatividade política e social, que decorrem da proeminência nas instâncias de decisão daqueles setores com maior peso econômico e, por conseguinte, com maior organização. ${ }^{13}$ É clara a influència que a estrutura econômica tem nas desigualdades da distribuição do poder social, portanto a sua modificação é a chave para se superar a relação inversamente proporcional entre a necessidade da participação e a sua possibilidade, já que os que mais necessitam participar são justamente os que menos podem fazê-lo. Entretanto, também é possivel admitir que os mecanismos de participação possam adaptar ou aliviar as desigualdades e gerar condições para legitimar ou problematizar, respectivamente, o modelo de desenvolvimento que as envolve. A possibilidade de alterar as assimetrias da representação no sistema político depende, em primeiro lugar, do reconhecimento dos sujeitos sociais como sujeitos "politicos". Certamente, se no sistema político não existe o princípio da discriminação positiva, que favorece a inclusão de novos atores, ${ }^{14}$ a assimetria da representação social se fortalece. Além disso, ainda que se criem oportunidades para a expressão de outros agentes, suas possibilidades de influência real podem ficar neutralizadas pelas condições oferecidas, principalmente quando "de fato" a politização da sociedade diminui ao favorecer a fragmentação dos sujeitos e das práticas sociais ou se privilegiar uma relação, de natureza apenas constitutiva em vez de reguladora, da sociedade com a política e, em particular, com a máquina estatal.

Nessas condições, julgamos ser necessário questionar pelo menos três aspectos da institucionaiização da articulação Estado-sociedade civil para estimular a participação dos cidadãos nas instâncias governamentais, assim como se desenvolveu como tendência na América Latina dos últimos anos: os agentes da participação social, suas modalidades e âmbito de ação.

Em relação aos "sujeitos", a experiência mostra que, quando a participação assumiu formas orgânicas de institucionalização, o Estado 
tendeu a determinar um acesso diferenciado dos interesses sociais às instâncias de decisão, em função de seus próprios interesses. Concede, assim, menor peso quantitativo à função de representação dos interesses da sociedade (considerando-se que os órgãos habitualmente são mistos) ou estabelece mediações à escolha dos representantes da sociedade civil, procurando impedir que sejam as próprias organizações sociais a elegêlos ou discriminando as organizações que têm a faculdade de designar representantes sociais ou de concorrer para sua designação. O tema assume dimensão altamente problemática quando a representação se institui sob a forma de organismos de representação de interesses, pois exige que se preste especial atenção às organizações participantes e à maneira como elegem seus representantes. Os problemas podem, inclusive, persistir ainda quando a representação se institua por fórmulas eletivas, que correm o risco da manipulação partidária dos órgãos de participação ou de anulação da manifestação das organizações populares preexistentes.

Características semelhantes estão implícitas na escolha das "modalidades de participação social". Em si mesma, a necessidade de institucionalizar formas de articulação do Estado com a sociedade civil e captar suas demandas não deixa dúvidas. Entretanto, é discutível circunscrevê-las a uma única modalidiade - o acordo, por exemplo - como vem sendo a tendência geral, principalmente se admitirmos que o controle social tanto quanto a interpelação politica ou o estabelecimento de instâncias de confrontação propositiva podem ser modos mais válidos de defesa dos interesses da sociedade ou de tornar públicos os conflitos, em circunstâncias em que não é aconselhável ou possível obter o consenso politico.

As modalidades de participação que são estimuladas têm, por sua vez, implicações sobre os sujeitos envolvidos. Obviamente, se certas formas de participação exigem um nivel de organização predeterminado por parte dos sujeitos, isso pressupõe a exclusão de amplos segmentos da sociedade que carecem de uma organização específica. Além disso, embora de modo menos evidente, constata-se a ocorrência de predeterminação dos sujeitos diante das próprias formas de participação oferecidas pelas instâncias governamentais. O claro privilégio, que se percebe na América Latina, 15 dado aos sujeitos "clientes" ou "consumidores" em detrimento dos sujeitos políticos, afeta diretamente a capacidade da sociedade exercer uma função crítica e de controle que transcenda os interesses particulares, assim como favorece o estabelecimento de uma relação mais mercantil que política com as instituições públicas (RISTREPO, 1995). Tal orientação pressupõe como tendência a exclusão de agentes, uma vez que mobiliza capacidades técnicas que não estão necessariamente presentes nos sujeitos sociais correspondentes, assim como assinala uma 
distorção dos esquemas de relação preconizados, ao pressupor que, mais do que o confronto de perspectivas, ${ }^{16}$ o que estaria em jogo seria a otimização das decisões, que seriam tomadas como despolitizadas.

Por outro lado, em relação ao "âmbito da participação social", cabe considerar que a limitar às esferas locais pode cerceá-la, por envolver sua fragmentação. De fato, a tendência clara, na América Latina, é a de favorecer a participação dos cidadãos nos processos de descentralização. A necessidade disso, em geral, não é discutivel pois se reconhece que a proximidade com as questões público-estatais estimula o envolvimento dos cidadãos. Entretanto, não se trata de uma relação automática, não só porque, no âmbito local, os órgãos de governo podem reproduzir as mesmas relações patrimoniais ou clientelistas que suscitam na esfera central, mas também porque, habitualmente, as principais decisões que afetam a vida local não se circunscrevem a este âmbito. Portanto, ainda que existam matérias sobre as quais tomar decisão - condição que nem sempre é satisfeita, dada a debilidade de muitos processos de transferência de competências e, principalmente, da mobilização de recursos para exercer tais competências - a experiência acumulada evidencia que, ao se estabelecerem mecanismos de participação dos cidadãos em processos de descentralização, pode-se produzir sérias distorções se não for questionada a conformação das máquinas governamentais na esfera local, se não forem consideradas as inter-relações dos diferentes niveis de governo nem se fizer a abordagem, necessariamente, inter-setorial dos fenômenos.

A fragmentação da prática participativa, que pode advir de abordagens parciais da relação descentralização-participação dos cidadãos, também pode ser suscitada quando esta só se associa a âmbitos estritamente setoriais. Como já destacamos, se apreciarmos globalmente a oferta governamental de mecanismos de participação, poderemos verificar que essa tendência também se nota na América Latina, dado que uma parte significativa das formas de participação desenvolvidas está diretamente vinculada às necessidades impostas pelos diferentes niveis governamentais, o que, além de gerar saturação dos sujeitos sociais, parece ter sérias implicações na possibilidade de se detectarem as problemáticas mais globais que afetam a vida coletiva. ${ }^{17}$

Enfim, o que claramente tentamos enunciar é que a geração de mecanismos de participação social não estimula necessariamente a organização social, mas pode, em contrapartida, vir a se constituir em desarticulação do tecido social e fortalecer as assimetrias da representação social, redundando no enfraquecimento da sociedade civil.

Entretanto, se admitimos que o Estado não só contribuiu para o estreitamento e a submissão da sociedade, mas também estimulou o acesso diferenciado a suas instâncias de decisão, devemos convir que a 
ele cabe a responsabilidade crucial de estabelecer condições que aumentem a capacidade de representação e de influência, particularmente, dos atores tradicionalmente excluídos, para que possam ter acesso a tais niveis de decisão e se expressem com autonomia frente à máquina estatal. É necessária, conforme já insinuamos, a criação de oportunidades de participação expressamente dirigidas a tais atores, que envolvam o seu reconhecimento como sujeitos políticos, bem como o respeito às organizações sociais preexistentes ou ainda aos setores da sociedade em que a organização não exista. É igualmente importante que o fomento dessa participação não se viabilize por meio de fórmulas instrumentais, fragmentárias ou rígidas. Trata-se de uma postura cujo objetivo é a politização das relações entre o Estado e a sociedade, de modo que esta disponha de condições para exercer uma função de critica e de controle sobre aquele. No entanto, o que as experiências em curso mostram é que esta é uma tarefa extremamente complicada, sobretudo devido às limitações do Estado para enfrentá-la, ao alcance da participação dos cidadãos e às suas condições sociopoliticas.

Enfim, está em jogo a estruturação de novas relações de poder, cuja viabilidade está condicionada à superação de sistemas políticos precários, em grande parte privatizados e caracterizados pelo autoritarismo. Podem estes sistemas promover a ampliação da participação dos cidadãos? Pode esta sobreviver, sem serem modificadas, estruturalmente, tais relações? Como a sociedade civil, nas condições atuais de crescente fragmentação e desintegração social, pode aumentar seu poder de pressão em favor da democratização do Estado?

Por outro lado, persiste o problema relativo ao alcance da participação dos cidadãos. É esta participação um instrumento para a democratização do Estado, que possa contribuir para realizar o politico na política, ou se trata de um substitutivo da participação política? Até agora, tem-se considerado que, predominantemente, a participação dos cidadãos produz a intervenção em ações públicas, mas só como manifestação e defesa de interesses particulares (coletivos e difusos). Desse modo, só poderia complementar (e não substituir) a participação política realizada pelos partidos politicos, contribuindo (e não interferindo) nos processos de formação de políticas e de tomadas de decisões públicas. Entretanto, ainda que esteja assim balizada a amplitude da participação dos cidadãos, devese reconhecer que existe uma tensão entre ela e a participação política, tensão esta que pode chegar a níveis críticos na medida em que se mantenha a tendência à desnaturalização dos movimentos de representação de interesses particulares através de sua conversão em partidos políticos, que se tornam, cada vez mais, aparatos instrumentais, que não agregam demandas mas expressam uma somatória de interesses particulares.

Nesse sentido, cabe considerar que a participação dos cidadãos, 
confrontada com partidos frágeis e, em geral, com um sistema de representação política em crise, pode constituir-se em uma forma de sedimentar o corporativismo e dar o monopólio do processo político a grupos que representem interesses organizados mas de caráter estritamente setorial e que, em decorrência de sua capacidade de controlar determinadas forças sociais, conspirem contra uma regra pluralista de formação das políticas. Desse modo, não há uma solução consistente para a criação de mecanismos que agreguem interesses, conforme postula FALETTO (1987:147), "o fortalecimento da sociedade civil, que norteia a ação meritória dos movimentos sociais, pode vir a resultar na primazia do privado sobre o público e na redução da política a um confuso cruzamento de conflitos, negociações e acordos, que se caracterizem tão-somente pelo imediatismo, no qual a política consistiria na administração tecnocrática do existente e, paradoxalmente, seria o Estado, como burocracia, a única garantia da ordem social".

Considerando tais questões, torna-se essencial o questionamento sobre o grau de influência dos processos de reforma do Estado, em curso na América Latina, na alteração de sua dimensão político-institucional, por meio de reformas políticas (eleitorais, de democratização dos partidos políticos e dos parlamentos), de reformas jurídicas (efetividade dos direitos e garantias da legalidade democrática) e de processos de descentralização político-administrativa, que criem um modelo institucional estável, aumentem a representatividade política e evitem a orientação patrimonialista e clientelista da máquina administrativa. Caso isso não se estabeleça, a dimensão autoritária permanecerá fortemente mesclada à democracia latino-americana (O'DONELL, 1993), impedindo o exercício da cidadania em amplas esferas e a amplos segmentos étnicos e de classe, bem como manter-se-á uma orientação particularista dos órgãos estatais e persistirá a confusão entre as esferas do público e do privado (RABOTNIKOF, 1993). Se assim for, admitimos que a construção do público a partir do privado social permanecerá interdita, ainda na segunda dimensão que abordamos a seguir.

\section{b) A participação da sociedade civil na gestão de programas ou serviços públicos}

Atualmente, várias circunstâncias e vários atores juntam-se na demanda por maior participação da sociedade civil na gestão de programas ou serviços, sobretudo no campo social. O Estado, movido, em grande parte, pela crise fiscal ou pela consciência de seus limites operacionais, parece inclinar-se mais e mais ao concurso de outros atores no desenvolvimento de suas atividades. Os usuários, em busca de maior qualidade dos serviços públicos, começam a se tornar favoráveis à provisão privada desses serviços. Muitas organizações não-governamentais, 
ante a escassez das fontes de financiamento tradicionais, buscam se associar a instâncias governamentais. Os organismos internacionais uns na fase de revisão dos modelos de prestação de serviços sociais pelo setor público, outros sob o argumento das virtudes intrínsecas ao envolvimento dos beneficiários - também reclamam por um papel mais ativo da sociedade civil.

Assim, além das ações que correspondem ao voluntariado, começase a promover a colaboração mútua, mediante a criação de associações que executem programas públicos, a transferência de funções do Estado a segmentos da sociedade para que as executem diretamente, o financiamento público a ações desempenhadas por organizações não-governamentais - ONGs - ou mediante a descentralização nos beneficiários da administração de gastos públicos.

A multiplicação de iniciativas como essas talvez pudesse servir de base para se afirmar estar em curso uma transformação real nos modelos institucionais de prestação de serviços públicos, que asseguraria não só maior peso participativo à sociedade, mas também melhor qualidade dos serviços, em uma nova institucionalidade pública. Cabe, nesse sentido, avaliar se tais iniciativas implicam a criação de relações de poder compartilhado e, inclusive de cessão de poder, inseridas no propósito de que o público não se esgote no estatal, e se realmente significam que está em desenvolvimento uma "cultura de co-responsabilidade política e social". A colaboração de diversos atores estatais e sociais como "sócios" no desenvolvimento de ações poderia estar delineando o sentido de "produção social" da saúde, da educação etc., e contribuindo para combater as culturas do paternalismo e do individualismo, mas as questões centrais que parecem estar em jogo são, de um lado, a possibilidade de criar oportunidades para aumentar a capacidade de desenvolvimento da organização social e, de outro, de ampliar a oferta, a qualidade e a eficiência na prestação dos serviços públicos, contribuindo para a maior eqüidade social.

Entretanto, as evidências práticas não têm sido muito animadoras nem os estudos sobre esses fenômenos são conclusivos.

Investigações de casos reais ${ }^{18}$ mostram que o envolvimento de consumidores, voluntariamente, na produção de serviços públicos, aumenta a qualidade destes, por melhor os ajustar às necessidades dos usuários, mas, por outro lado, incrementa os custos; demonstram também que tal envolvimento está condicionado à assistência financeira do Estado e que, dadas as resistências burocráticas, tende a ficar restrito a serviços públicos periféricos ou suplementares.

Por outro lado, trabalhos referentes à prestação de serviços públicos por parte de ONGs reconhecem que sua eficiência e efetividade estão em grande parte associadas a resultados de pequena escala. Isto põe em dúvida não só sua capacidade de responder às demandas e ampliar seu 
atendimento, mas também a estabilidade e a sustentabilidade dos programas executados por esse tipo de organização.

A experiência mostra também que a participação da comunidade em programas públicos está associada aos custos da ocasião de sua execução, crescentemente elevados devido à crise, o que privilegia as atividades mais estritamente vinculadas à sobrevivência.

Por fim, os programas sociais desenvolvidos na América Latina, em sistema de co-responsabilidade com a sociedade civil, mostram, entre seus resultados, a fragmentação dos espaços de decisão e de ação social, danos ao tecido social existente, juntamente com a instabilidade das formas de organização devido às condições que as instâncias governamentais estabelecem para credenciá-las a receber contribuições financeiras.

Considerando essas evidências, é possivel concluir que as oportunidades reais de se criar a autogestão ou a co-gestão social de recursos públicos, que envolvem a possibilidade de abertura de novos espaços públicos, não são automáticas mas relativas e condicionadas a uma série de fatores relacionados com transformações institucionais e culturais da máquina governamental e com o tipo de ator social envolvido.

De fato, aceita-se que a efetividade dos esforços para transferir funções à sociedade civil esteja centrada na possibilidade de que o conceito "público" não se esgote no "estatal". Assim, tais esforços não podem ser julgados apenas em função do grau de descentralização dos recursos, das decisões ou das responsabilidades estatais, mas principalmente em função do grau de organização que promovem e do fortalecimento de novos segmentos da sociedade para aumentar seu acesso aos recursos de poder e aos frutos do bem-estar.

Isso coloca a atenção na determinação do nivel de contribuição que cada modelo de relacionamento Estado-sociedade traz ao incremento da eficiência e da efetividade na prestação dos serviços públicos, bem como na sua capacidade de preservar o exercicio da responsabilidade pública e fortalecer a sociedade civil. A resposta a tais questões constitui a chave para os argumentos que buscam legitimar a privatização da produção pública dos serviços sociais sob a alegação de uma suposta superioridade técnica do setor privado.

Sendo assim, jả que muitas variáveis estão articuladas ao se empregar como marco de referência teórica a capacidade de construção do público, deve-se reconhecer a heterogeneidade dos atores que formam a sociedade civil, assim como as próprias imprecisões do termo. ${ }^{19} \mathrm{~A}$ tendência predominante é a de admitir que a sociedade civil constitui um "terceiro setor", distinto do Estado e do mercado (a empresa privada), que identifica o espaço das associações humanas não fundadas na coerção do Estado, mas sim na interação comunicativa para sua reprodução. ${ }^{20} \mathrm{De}$ qualquer modo, certamente tem implicações diversas a transferência da 
produção de bens públicos a entidades do setor empresarial, a organismos sem fins lucrativos, a organizações comunitárias de base ou a voluntários ou beneficiários, principalmente se se levar em conta a capacidade de desenvolvimento da organização social e, particularmente, os objetivos de fomento à participação social e ao incremento das capacidades comunitárias.

Há, de fato, esquemas de relação que tentam mobilizar diretamente as organizações que preconizam a participação comunitária. Existem, inclusive, em certos paises, normas legais que favorecem expressamente os convênios com organizações comunitárias. Na Argentina, por exemplo, há vários anos, a execução de obras por consórcios ou cooperativas de vizinhos está prevista na legislação de várias provincias. Mais recentemente, a legislação colombiana também favoreceu a contratação de obras por organizações sociais e comunitárias preexistentes.

Existem outros casos em que tais organizações são criadas especialmente para a execução de certas atividades. A Colômbia, por exemplo, promoveu, por meio de diversos dispositivos legais, a criação de organismos de ação comunitária (Juntas de Ação Comunitária e Juntas de Habitação Comunitária) como associações sem fins lucrativos, para administrar serviços públicos (como redes de água e de esgotos), construir, mediante autogestão, cbras de infra-estrutura para serviços e equipamentos comunitários destinados às famílias filiadas e até para exercer função de economia social por meio de Comitês de Trabalho Empresarial, de cujo número depende a manutenção da procuradoria. Outro caso relevante dessa mesma orientação é o do Programa do Copo de Leite, no Peru, organizado por comitês de mães, cuja importância reside não apenas na participação comunitária mas também na sua evolução organizacional, que alcançou a forma de autogestão, com amplitude nacional.

É possivel, portanto, aplicar também o princípio da discriminação positiva ao se firmar convênios para a descentralização da produção de bens públicos, de modo a favorecer diretamente as organizações sociais que mobilizam o setor não mercantil e que podem contribuir para o fortalecimento do setor popular, uma vez que atuam como mobilizadoras da participação social desse segmento.

Ainda nesses casos, porém, admitindo-se que o ator social que atua como sujeito da participação possa ser construído pelo próprio Estado, que determina a criação de instâncias especiais para tal fim, a experiência mostra que o problema de articulação dessas associações com as organizações sociais preexistentes deve ser cuidadosamente avaliado, levando-se em conta a tensão que pode ser produzida entre elas. Os resultados que os governos exibem em matéria de promoção da organização social pela constituição de comitês especiais têm-se traduzido, em muitas oportunidades, na ruptura do tecido social preexistente. 
De qualquer maneira, importa ressaltar que a determinação dos atores é, em si mesma, uma questão problemática, sobretudo se considerarmos que, entre organizações com características aparentemente comuns, podem existir, na prática, diferenças substanciais. Reconhece-se, atualmente, que no próprio setor das ONGs existe uma grande variedade de organizações, que desenvolvem diferentes tipos de aproximação com a participação social. ${ }^{21}$ Admite-se, inclusive, que nem todas elas promovam necessariamente a criatividade local ou criem novos canais de pressão dos setores excluídos, mas, ao contrário, possam desenvolver relações clientelistas com o Estado ou com as agências de fomento e contribuir para a despolitização social. Os mesmos traços têm sido detectados em organizações populares de base (STIEFEL \& WOLFE, 1994), o que nos adverte sobre a necessidade de, em vez de defender a virtude intrinseca da sociedade civil, reconhecer-se a heterogeneidade desse setor e o papel relevante de atores e práticas tradicionais ou informais, que não estão necessariamente englobados pelo conceito de sociedade "civil" (FERNANDES, 1994).

A diferença entre possiveis atores sociais deve ser analisada não só com relação à sua inclinação para fomentar a participação social, mas também à sua própria efetividade e eficiência na prestação dos serviços públicos. Assim, se se preconiza como objetivo a incorporação da sociedade civil na luta contra a pobreza, é necessário analisar em profundidade a eficácia dos diferentes atores na criação de oportunidades de geração de renda e de emprego. Isto põe em relevo outra contradição que pode estar aflorando no campo da organização social e que já começou a ser apresentada pelas ONGs (LOPEZ, 1995): a tensão entre as tarefas políticas e o objetivo de produção de serviços. Em um plano mais específico, STIEFEL \& WOLFE (1994:217) notam a contradição existente entre o enfoque de "projetos" (limitados no tempo e na abrangência), dado pelos governos à participação social e a mesma participação focalizada como esforços organizados e coletivos dos excluidos em defesa de suas vidas. A participação dos governos (e, $\mathrm{cm}$ geral, das agências fomentadoras) significa intervenções setoriais, limitadas no tempo e com resultados definidos quantitativamente, enquanto a emergência de organizações participativas supõe, ao contrário, um largo tempo, durante o qual as relações sociais são gradualmente modificadas; introduz incertezas dificeis de serem equacionadas sob pontos de vista instrumentais, tem resultados menos tangiveis e apresenta implicações na distribuição do poder.

Questões como as já mencionadas nos levam a considerar que o Estado, ao transferir funções à sociedade para a ampliação do espaço público, deve confrontar o conjunto de solicitações e avaliar as diversas opções de ação em função da probabilidade de elas fortalecerem não só a sociedade mercantil, mas também de transformarem o paradigma das relações Estado-sociedade, dando primazia a esta. 
Com isto, volta-se ao duplo desafio, já indicado, a ser enfrentado pelo Estado: de um lado, a não-abdicação de sua responsabilidade pública e, de outro, a mudança no enfoque de suas relações com a sociedade. Se o primeiro não estiver devidamente assegurado, a descentralização das funções produtivas do Estado pode resultar em maior desorganização quantitativa e qualitativa dos serviços públicos, particularmente daqueles destinados aos segmentos mais pobres, tal como provam várias experiências de privatização de setores empresariais não submetidos a regulamentações (OIT, 1995). O mesmo efeito pode resultar da produção de bens públicos por organizações sem fins lucrativos ou voluntárias (BARENSTEIN, 1994) se não existir apoio financeiro do Estado, ao menos até ficar assegurada a plena sustentabilidade do empreendimento (questão nem sempre possivel). A responsabilidade pública do Estado, portanto, expressa-se, em primeira instância, em termos de financiamentos e de regulamentações apropriadas. Porém, para enfrentar o segundo desafio - a mudança do paradigma das relações Estado-sociedade - os conteúdos e as diretrizes desses financiamentos e regulamentações podem adquirir conotações precisas. De fato, se a ação do Estado pretende favorecer a organização social, são questões cruciais a redefinição de sua autoridade e a reorientação de sua ação, de modo a colocar, em primeiro plano, a perspectiva das solicitações da sociedade para esse fim - e não as suas próprias perspectivas. Em decorrência dessas demandas, o Estado pode orientar diferentes esquemas de financiamento.

Merece atenção especial o caso da transferência de recursos governamentais a entidades privadas, para que estas forneçam serviços públicos. Tal transferência se dá por diversos mecanismos como compra de serviços, licitações, concursos, convênios etc., que precisam ser analisados segundo sua possibilidade de favorecer a abertura de novos espaços públicos, assim como de suas vantagens e desvantagens. Admite-se (DE LA MAZA, 1993) que a criatividade em política social possa ser desenvolvida por processos de concurso mais ou menos abertos, em que os candidatos a executores apresentem propostas de trabalho, sem ficar limitados a participar de licitações de obras previamente definidas. Essa possibilidade foi aproveitada pelo Fundo de Investimento Social - FOSIS, do Chile, na tentativa de superar uma das limitações que os mecanismos de licitação impõem à sociedade civil, que é o de lhe destinar o papel de simples executor ou de restringir a ação da sociedade à reação a uma oferta do Estado. A questão-chave, no caso, envolve a atuação do Estado em função das demandas da sociedade. Conforme destacamos anteriormente (1991), as experiências de participação do cidadão com maior êxito conseguiram inverter o paradigma da relação Estado-sociedade em favor desta, dando-lhe garantias de total autonomia institucional. PRATES \& ANIRADE (1985) ilustram esse modelo com programas de planeja- 
mento participativo, que consistem na oferta de recursos por parte do Estado a comunidades de baixa renda que, por suas associações formais, propõem projetos de seu interesse que, uma vez executados, esgotam a relação institucional Estado-comunidade. As variações do modelo são múltiplas, mas a consciência de que sua aplicação exige níveis mínimos de organização e de capacidade de expressão social impõe ao Estado o desafio de contribuir para que tais condições sejam satisfeitas. Neste sentido, HOPENHAYN (1995:4,3), reconhecendo que a "destinação de recursos públicos em contrapartida a demandas ou projetos de beneficiários organizados não tem, necessariamente, um efeito focalizado nos segmentos mais pobres", ilustra o trabalho que se poderia realizar com tal objetivo com o exemplo do Fundo de Mudança Social - FIS, da Bolívia, que estabeleceu um sistema de promoção ativa como instrumento para orientar a demanda dos setores mais pobres. ${ }^{22}$

Ainda que pareça possivel enfrentar alguns problemas relacionados a esses mecanismos, fica demonstrado claramente que a opção pela modalidade de financiamento de programas implica outras decisõeschave relativas às formas de expressão social, que podem apresentar diferentes graus de envolvimento dos atores sociais e, por conseguinte, ter implicações diferentes no desenvolvimento dos programas.

O assunto é também pertinente ao se decidir sobre o tipo de financiamento, considerando-se que a decisão por um financiamento parcial pode ter como fundamento a necessidade de cultivar a co-responsabilidade, dando ao financiamento a característica de retribuição ao esforço da própria comunidade. Sob essa perspectiva, não só se devem estudar as lições oferecidas por programas baseados no princípio da co-responsabilidade, como o Programa Nacional de Solidariedade - PRONASOL, do México, mas também explorar os mecanismos mais eficazes para a canalização de recursos em forma de créditos e doações à sociedade civil, levando-se em conta as diversas opções que começam a surgir: bancos de desenvolvimento comunitário, instituições locais de concessão de doações com patrimônio próprio, fundos de empréstimos comunitários, cooperativas de crédito para o desenvolvimento comunitário, sociedades financeiras, associações empresariais, entidades paraestatais etc. (Esquel Group Foundation, 1993.)

Há, no entanto, outros problemas quanto à complementação de ações entre as instâncias governamentais e a sociedade civil, por meio de financiamentos destinados a essa. Estudos de casos envolvendo financiamentos de ONGs mostram que estas têm encontrado significativos entraves e limitações burocráticas, que põem em dúvida a conveniência de prosseguir-se nesse caminho, dado que as ONGs acabam subsidiando a oferta de serviços por parte do Estado (IRARRÁzABAL et al, 1993).

Por outro lado, também há evidências da utilização de recursos 
públicos para fins privados, o que demonstra que o tema da responsabilidade pública diz respeito não só à entidade estatal mas também às próprias organizações sociais.

Esses questionamentos obrigam-nos a fazer duas considerações de caráter mais geral sobre o papel de regulador que se impõe ao Estado e sobre as condições de transformação da máquina burocrática, que os novos modos de relação entre ele e a sociedade exigem. Ambas, por sua vez, levam à pergunta: como o Estado pode desenvolver condições favoráveis para a ação privada, que preservem tanto a autonomia social quanto o exercício da responsabilidade pública?

Quando o Estado atua como fonte de recursos financeiros, é claro que se faz necessário fixar limites à ação discricionária das entidades privadas quanto ao uso dos recursos públicos. Isto exige um "referencial regulador", que proporcione o controle sobre os atores sociais, mas que, por sua vez, não prejudique sua autonomia. Provavelmente, sempre existirá esse tipo de tensão, porém parece existirem modos de aliviá-la. Nesse sentido, além das questões de ordem técnica, relativas à transparência e à coerência das normas e à força das instituições encarregadas de as fazer cumprir, poder-se-ia propor a revisão da própria concepção dos mecanismos institucionais reguladores e analisar a hipótese, entre outras, da adoção do conceito de "controladoria social". Isso pressupõe que a responsabilidade pela "exigência de prestação de contas" não recaia apenas sobre o Estado, que a exerce em relação às organizações sociais receptoras de recursos e responsabilidades, mas também que seja assumida pelos próprios cidadãos receptores dos serviços. A atuação destes não deveria apenas se destinar a físcalizar tais organizações, mas a exigir a prestação de contas dos organismos estatais financiadores, inclusive com a avaliação da qualidade das normas regulamentadoras. Assim, os cidadãos poderiam mediar a tensão entre a autonomia das associações socia is e controle do Estado, e garantir que o dever da responsabilidade seja exercido por todos os atores.

Em algumas das propostas comentadas, começam a ser vislumbrados avanços. Por exemplo, o PRONASOL, do México, prevê expressamente a figura da "controladoria social". Para cobrar a responsabilidade dos governantes e dos funcionários públicos, foi adotada em outros países, recentemente e de forma ampla. Na Colômbia, por exemplo, a "inspetoria dos cidadãos" — individual e coletiva - foi estabelecida, normativamente, por diversas entidades setoriais e territoriais, registrandose estudos para o estabelecimento de uma política geral para seu fortalecimento. De particular interesse se revestem, nesse caso, o controle e a vigilância dos processos de contratação, para que, entre outros, se atenda aos critérios de democratização da gestão pública - pelo estabelecimento de contratos com organizações sociais e comunitárias - e se garanta 
o cumprimento das metas fisicas, financeiras e qualitativas. Um caso similar está previsto na recente Lei de Participação Popular, da Bolivia, que determina a criação de Comitês de Vigilância para articular as organizações de base com os governos municipais.

É óbvio que estas experiências são muito recentes para permitir a avaliação ampla de seus resultados, mas, em todo caso, propõem uma solução para o problema do controle mais direto dos cidadãos sobre a administração pública - o que é fundamental - do que sobre as organizações sociais que começam a executar funções públicas. De qualquer maneira, é evidente que um dos temas-chave do futuro será o controle, principalmente porque já há consciência de um claro déficit nessa matéria, depois dos avanços na transferência de empresas e serviços públicos ao setor privado mercantil, que provavelmente se incrementará com a consolidação da tendência de descentralizar serviços sociais também para organizações sem fins lucrativos.

A necessidade de revisar os esquemas e as técnicas de controle tem por objetivo maximizar a responsabilidade pública e evitar o constrangimento da sociedade civil, assim como assegurar a eficiência e a qualidade da prestação de serviços. Regulamentação e desregulamentação são, portanto, dois problemas que precisam ser incorporados à discussão. Nesse sentido, é importante observar o desenvolvimento de soluções inovadoras que estão sendo implementadas atualmente, tal como a que está prevista no Brasil, no âmbito da reforma do Estado, que consiste em dotar de autonomia financeira e administrativa os serviços sociais do Estado, transformando-os em fundações de direito privado ("organizações sociais"), de modo a assegurar maior flexibilidade, eficiência e qualidade na prestação dos serviços e que, para tais efeitos, prevê não apenas um controle dos resultados de tais organizações pelo Estado e pela sociedade mas também a implantação do sistema de contratos de gestão para assegurar direitos e obrigações reciprocas entre ele e as organizações sociais (Bresser Pereira, 1995).

Por fim, nossa última hipótese sustenta que "a construção da viabilidade da recomposição do esquema de poder entre o Estado e a sociedade está vinculada ao modo de configuração do aparelho público e de seus estilos de gestão". Admitimos que este é um problema central, já que a maioria das experiências em curso mostram que as burocracias públicas tendem apenas a aceitar como funções da participação social as que maximizam seus próprios objetivos (informação ou oferta de mãode-obra e de outros recursos) e que, não obstante as declarações em favor da abertura do Estado à sociedade, na prática ele tende a assumir uma atitude de oposição a esta (NAvArRo, 1993). Nesse quadro, um dos problemas a resolver é o desenvolvimento da capacidade de as instâncias governamentais aceitarem a existência do conflito de interesses entre as 
partes envolvidas em uma decisão e, por conseguinte, a necessidade de gerar um estilo de gestão que permita a cada uma das partes construir sua própria força organizacional para enfrentar o processo de negociação com as demais. Disso deriva a exigência de revisar os modelos organizacionais da máquina governamental, inclusive o paradigma dominante do Direito Administrativo.

Já se destacou (PraTs, 1995) que existe uma contradição significativa entre o Direito Administrativo (e o modelo burocrático que lhe está funcionalmente relacionado) e as demandas de autonomia - e de flexibilidade - que os novos desenvolvimentos da administração propõem em função dos requisitos de eficácia e eficiência. O problema, entretanto, aumenta em face das demandas por participação social. É claro que, diante de processos extremamente definidos ou dominados por hierarquias rigidas, a intervenção dos cidadãos torna-se uma falácia. Por outro lado, a experiência também mostra que deixar a ativação dos mecanismos de participação livres ao capricho dos funcionários governamentais cerceia suas possibilidades. Assim, não só a tensão entre a flexibilidade de organização e a normatização básica deverá ser reconhecida no futuro, como também a tensão relacionada à supra-ordenação e subordinação próprias da hierarquia burocrática versus as relações simétricas, necessárias ao incremento da capacidade de deliberação da sociedade.

De modo mais específico, os novos estudos chamam também a atenção sobre a dupla exigência que se impõe ao governo: i) reforçar sua capacidade quanto à administração financeira, às técnicas de participação e à identificação de novos associados; ii) criar um contexto de habilitação para a sociedade civil, o que pode incluir a reforma fiscal (por exemplo, a possibilidade de outorgar isenções e deduções tributárias a doações beneficentes), possibilitando mecanismos que efetivem a responsabilidade e o estabelecimento de um referencial regulamentador apropriado para a fazer prosperar. (Esquel Group Foundation, 1993:13-14.)

A criação de oportunidades para a participação da sociedade civil na execução de programas e serviços públicos, de fato, gera uma série de exigências ao Estado, tanto em termos de recursos e regulamentações (ou desregulamentações, conforme o caso) quanto em relação a modelos institucionais apropriados, qualquer que seja o tipo de relação que se pretenda favorecer.

Podem existir áreas em que seja mais apropriada a retração do Estado em relação às vantagens comparativas de um ou de outro sctor. Por exemplo, sustenta-se que um dos âmbitos em que as ONGs devem substituir o Estado, dadas as limitações deste, reside na identificação, gestão e formulação de projetos e programas sociais de nivel local (IRARRAZABAL et al, 1993:59). Identificar quais são estas áreas não deve implicar, entretanto, que o Estado deixe de se responsabilizar por elas. Pelo 
menos, sempre lhe restará sua participação de apoio e de controle, especificados anteriormente - o que provavelmente exigirá o fortalecimento de sua capacidade de obter informação e proceder à análise política, entre outras funções.

No entanto, o desafio mais importante e diretamente ligado ao Estado é "a mudança de enfoque de suas relações com a sociedade civil". Em vez de pretender que esta se aproxime dele, por meio de canais institucionais criados em função de seus objetivos e necessidades, o que se preconiza é a inversão desse paradigma, de modo a apoiar a sociedade civil no contexto da preservação de sua autonomia institucional e não sufocar sua capacidade de negociar livremente as melhores opções para seu desenvolvimento. Confirma essa necessidade o fato de que, cada vez mais, se formem organizações e amplos movimentos sociais para realizar suas próprias estratégias de sobrevivência, os quais assumem um papel público de luta contra a pobreza, inclusive mediante a produção direta de bens públicos.

A propósito, é preciso considerar, ainda, que as práticas reivindicatórias e a mobilização de recursos sociais para pressionar em favor da redefinição de propostas políticas são os espaços por excelência da ação da sociedade civil. É preciso notar que a sociedade "também, subsidiariamente", participa da execução de programas e serviços sociais, combinando pressões e mobilizações com novas formas de interlocução pública e de interpelação política para a defesa de seus direitos, para o estabelecimento de critérios públicos na utilização dos recursos e bens de que depende a qualidade de vida das maiorias, assim como para a introdução de novos temas na agenda pública estatal.

A consciência disso remete ao primeiro plano de abordagem deste trabalho, inclusive em um sentido mais amplo que o tradicional. A perspectiva que adotamos de que a sociedade deve poder recuperar o espaço público implica, principalmente, o exercício de uma função de crítica e de controle sobre o Estado, para ampliar sua influência sobre ele. A "nova relação institucional pública", se bem que preconize a superação da dicotomia Estado-sociedade, não pretende anular as fronteiras de um e de outro. No âmbito privado, é possivel — e necessário — assumir a produção de bens públicos, sempre que isto, por sua vez, não suponha que o Estado abdique de sua responsabilidade pública e que, além disso, também a sociedade mantenha sua especificidade e exerça uma função reguladora sobre o Estado e a política. A "participação dos cidadãos" pode servir a esse propósito e alterar o desenho das políticas e a destinação dos gastos governamentais. Ainda assim, este é apenas um aspecto do problema: também é preciso que a representação das reivindicações dos cidadãos esteja presente no discurso dos partidos políticos e, sobretudo, no debate público. Ainda mais: tais reivindicações também apontam para a 
própria democratização da sociedade e para a ampliação do conceito de público às organizações sociais que atuam sobre o Estado (HABERMAS, 1986) e àquelas que produzem bens públicos. Desse modo, a democratização do Estado e a da sociedade, no contexto de fortalecimento da sociedade, passam a ser dois problemas mais estreitamente vinculados do que até agora se tem admitido. É possivel que a redefinição das relações entre eles determine não só em que aspectos e de que maneira ambos os setores podem se complementar mas também como se pode preservar o espaço de um e outro, para que, efetivamente, a esfera do público venha a se ampliar.

\section{Notas}

1 Vejam-sc, entre outros, os relatórios de Desenvolvimento Humano das Nações Unidas $(1993,1994)$ e da OIT (1995).

2 Habermas considera que o espaço público democrático corresponde a um nível localizado entre a esfera privada e o Estado, cuja função principal não ć apenas a de perceber $e$ identificar problemas que afetam o conjunto da sociedade, mas explicitá-los de mancira convincente e persuasiva, para que ejam incorporados e processados pelo sistema político. Suas contribuições mais recentes, de fato, projetam o desenvolvimento de um conceito normativo do público (1990).

3 Um excelente trabalho, a nosso ver, que percebe os diferentes sentidos atribuidos ao conceito de público e alguns de seus problemas, é o de RABOTNIKOF (1993).

4 A formulação habermasiana (1986) $\mathrm{c}$ uma das que mais diretamente se fundamentam $\mathrm{cm}$ uma análise do público conforme o que foi enunciado. Faz mais de trinta anos (na versão original de 1962), trouxe ao ccnário da ciência política não apenas um diagnóstico cmpírico da falência da esfora pública liberal, mas também, cono ele mesıno declara, "o aspecto normativo de uma visão democrática radical, que considera e converte em seu objetivo o $\mathrm{en}$ trelaçamento funcional do Estado e da sociedade, que objetivamente ocorre" (1992:439). Sua proposta atual (1990) defende a necessidade de modificar a idéia normativa de uma auto-organização da sociedade quando do surgimento da democracia de massas, que se propunha ao Estado de Bem-Estar Social, a qual torna patente a falácia de que os cidadãos "atuam sobre si mesmos" por meio das leis.

5 Como é bem conhecido, foi Marx quem contribuiu com a interpretação mais radical da esfera pública. Ele, neste sentido, questiona não apenas a idéia da representação do universo social pela esfera pública burguesa, mas também a própria capacidade de transformação dessa esfera, na medida em que a esfera econômica cstá perpassada pelo antagonismo das classes sociais e se baseia, portanto, na dominação.

6 A resposta a esta pergunta percorre toda a história do pensamento político. Contemporaneamente, a gama de respostas relaciona desde prescriçōes que justificam a redução do espaço de influência (teoria elitista) até formulaçooes que buscam a recuperação da idéia da demorracia direta.

7 Oszlac (1992) aponta essa direção, ressaltando que o poder acumulado é a chave para esclarecer quem define a agenda pública, quem ganha e quem paga os custos, entre outros. Pondera: "um poder menor do Estado diminui sua capacidade de fixar agendas e obter recursos para executá-las. Naturalmente, ao se fazer referência a um maior ou menor poder do Estado, é fundamental conhecer quem o controla". (Idem: 14.)

8 Bejarino (1994:53), entre outros, focaliza o fortalecimento politico do Estado na sua meIhor representatividade, quer dizer, na sua capacidade de assegurar o acesso a ele de forças 
politicas e sociais previamente excluidas do controle da máquina estatal, assim como $\mathrm{em}$ sua maior responsabilidade (accoumtability) frente á sociedade.

9 Scgundo Habermas (1990), os requisitos fundamentais para a constituiçào de um espaço público democrático são: a autonomia com relação ao sistema politico (de modo que a produçĩo de novos fundamentos normativos não seja orientada por ele) $\mathrm{e}$ a informalidade dos processos de formação de opinião, que podem atuar assim porque não estão sob a pressão de decisões.

10 Acolhemos aqui a expressão mais usual, que se relaciona diretamente à cxpressão de interesses coletivos e difusos nas esferas públicas estatais. Veja-se a discussão sobre esta abordagem em CUNILL (1991).

II Entre os autores classicos desta matéria está Patenan (1970), ao tratar das democracias ocidentais.

12 Veja-se a esse respeito, para o caso da Europa e, em particular, da Espanha, SiNChEZ MORON (1995).

13 Este é um problema particularmente importante para a ampliação do conceito de público, porque o grau de inserção na estrutura económico-social determina as possibilidades de participação. A CEPAL (1992) considera que a condição sociopolitica básica da cstratćgia de "Transformação Produtiva com Eqüidade", para obter-se a integração social de nivel simbólico, é o consenso, que tem, por sua vez, como condição a incorporação das demandas dos excluidos. Sustenta que a incorporação destes nos mecanisrnos de consenso torna necessária a criação de novos canais de representação $\mathrm{c}$ novas formas de articulação com o sistema político e afirma que a convocação para a geraçào de mecanismos para processar demandas dos setores menos articulados do setor produtivo noderno pode estimular, complementarmente, sua maior organizaçào. (Idem: 32.)

14 A expressão "novos atores" ć aqui utilizada para enfatizar a idéia de atores que até agora estão excluidos do controle da máquina estatal. Em sentido restrito, abrange tanto novos quanto velhos atores sociais.

I5 OCHOA e RESTREPO (1993), referindo-se à Colômbia (onde foi dado impulso significativo à participação do cidadão), ressaltam que a oferta governamental esteve basicamente orientada para a participação dos consumidores e não dos cidadãos que atuassem sobre objetivos intersetoriais de desenvolvimento ou sobre a coordenação das unidade de gestão.

16 Uma ampla literatura ressalta a necessidade dessa orientação. Veja-se, por exemplo, STIVERS (1990) c FISCHER (1993).

17 A abordagem dos cidadãos como consumidores ou usuários e o privilégio da participação setorial podem estar intimamente relacionados. Veja-se a esse respeito OCHOA e RESTRi:PO (1993) e RESTREPO (1995).

18 Veja-se a cste respeito BARENSTEIN (1994), que transcreve experiencias de paises desenvolvidos e subdesenvolvidos.

19 Vários trabalhos já começam a ressaltar as imprecisōes do conceito de sociedade civil, em sua base filosófica de categoria analitica. No que diz respeito à América Latina, veja-se FERNANDES (1994), que mostra que a "sociedade civil" pode ser apenas a ponta do iceberg e que, abaixo da linha de água, prevalecem práticas e sujeitos informais, cuja importância não pode ser desconsiderada. Desse modo, existe também ressalva à assimilação do conceito de sociedade civil ao universo da "cidadania", que a associaria a um subconjunto (pequeno) dos sujeitos sociais da América Latina.

20 Veja-se, por exemplo, Colien e Arato (1992).

21 Estudo promovido pelo BID sobre a intervenção de ONGs na prestação de serviços sociais focaliza as "organizaçòes de participaçào comunitaria", entendidas desse modo as organizações que desenvolvem a capacidade de intermediação entre as comunidades pobres es grupos de base nelas existentes, o governo ou outras organizaçòes nacionais c internacionais (NAvarRo, J.-C., 1993:5-6). Entretanto, é preciso reconhecer a importāncia que a participação da comunidade tem em tais organizaçōes, a qual pode ter diferentes formas c utilizar diversos meios, empregando a comunidade como voluntária, grupo de consulta ou decisório.

22 Veja-se, com relação a isso, o acompanhamento que faz o CEDAl do CLAD sobre os Fundos de Investimento Social no âmbito do Sistema Integrado c Analitico de Informação sobre Reforma do Estado - SIARE. 
BARENSTEIN, Jorge. "Gubernabilidad comparada a nivel local: nuevas tendencias y antiguos desafios." Reforma y Democracia: Revista del CLAD. Caracas, n. 1, 1994.

Bejarano, Ana Maria. "Recuperar el Estado para fortalecer la democracia." Análisis Político. Bogotá, n. 22, 1994.

BobBıo, Norberio. El futuro de la democracia. México: Fondo de Cultura Económica, 1986 (original de 1984).

Bresser Pereira, Luiz Carlos. "A reforma do aparelho do Estado c a Constituiçào Brasilcira." Brasilia: Ministério da Administração Federal e Reforma do Estado. Mimeo, 1995.

Calderón, Fernando; Reyna, José Luis. "La irrupción encubicrta. Oye, Pedro, te hablo a ti para que me escuches tu, Juan." David e Goliath. Buenos Aires, n. 57, 1990.

CAPElla, Juan Ramón. Los ciudadanos siervos. Madrid: Editorial Trotta, 1993.

CEPAL."Las dimensiones sociales de la transformación productiva con equidad." Santiago: Mimeo, 1992.

Cohen, Jean L.; ARATo, Andrew. Civil society and political theory: Cambridge: The MIT Press, 1992.

Cunill, Nuria. Participación ciudadana: dilemas y perspectivas para la democratización de los Estados latinoamericanos. Caracas: CLAD, 1991.

DE LA MAZA, Gonzalo. "LoS organismos no gubernamentales y el FOSIS. Balance de tres años de relación." El sector no gubernamental y los Fondos de Inersión Social: la experiencia chilena. Gonzalo de la Maza, ed., Santiago: ECO, 1993.

Esquel Group Foundation. "Sociedad civil, Estado y mercado: una associación incipiente en procura de un desarollo equitativo." Estudo apresentado ao Fórum Social convocado pelo Banco Interamericano de Desenvolvimento c o Programa das Nações Unidas para o Desenvolvimento. Washington, D C.: 10 a 13 de feverciro de 1993. Mimeo.

Faletto, Enzo. "Propuestas para el cambio: movimientos sociales en la democracia." Nueva Sociedad. Caracas, n. 91, 1987.

Fernandes, Rubem Cesar. Privado porém priblico: o terceiro setor na América Latina. Rio de Janeiro: Relume-Dumara, 1994.

FiSher, Frank. "Citizen participation and the democratization of policy expertise: from theorical inquiry to practical cases." Policy Sciences. Dordrecht, vol. 26, n. 3, 1993.

Habermas, Jürgen. Hisłoria y critica de la opinión pública. México: Ediciones G. Gili, 1986 (original de 1962).

"Soberania popular como procedimento: um conceito normativo de espaço público." Novos Estudos CEBRAP. São Paulo, n. 26, 1990 (original de 1989).

"Further reflections on the public sphere." Habermas and the public sphere. Craig Caloun, comp. Cambridge: The MIT Press, 1992.

Hopenhayn, Martin. "Recomposición de actores en programas sociales: consideraciones desde la experiencia latinoamericana." Santiago, CEPAL. Mimeo, 1995.

IrARRÁzABAL, Ignácio el al. Organizaciones de participacion comunitaria: su lucha contra la pobreza en Chile. Washington: Departamento de Desenvolvimento Econômico e Social. Banco Interamericano de Desenvolvimento. Série de Documentos de Trabalho 154, 1993.

LECIINER, Norbert. "El proyecto neoconservador y la democracia." Crítica y ulopia. Buenos Aires, 1981.

La democratización en el contexto de una cultura post moderna. Santiago: FLACSO. Documentos de Trabajo, n. 232, 1986.

Reflexión acerca del Eslado democrático. Santiago: FLACSO, Seric Estudios Politicos, n. 20, 1992.

LOPEZ N.. José Luis. "Las organizaciones no gubernamentales de desarollo - ONGs. Sus desafios: pobreza y democracia." Caracas: CESAP. Mimco, 1995.

Navarro, Juan Carlos. Organizaciones de participución comunitaria: su contribución a la lucha contra la pobreza. Washington: Departamento de Desenvolvimento Econômico e Social. Banco Interamericano de Desenvolvimento. Série de Documentos de Trabalho 158 . 1993.

OCHOA, Doris; Restrepo Botero, Dario Indalecio. "El estado del arte de la descentralización política y de la oferta pública en participación ciudadana y comunitaria." Santafé de Bogotá: FESCOL, FAUS. Mimeo, 1993.

O’Donnell, Guillermo. "Estado. democratización y ciudadania." Nueva Sociedad. Caracas: n. $128,1993$. 
OIT. "La incidencia del ajuste estructural en los servicios públicos (eficacia, mejora de la calidad y condiciones de trabajo)." Genebra, OlT. Mimeo, 1995.

OSZI.AK, Oscar. "Estado y sociedad: las nucvas fronteras." Buenos Aires. Mimeo, 1992.

Pateman, Carole. Participation and democrustic theon: Cambridge: University Press, 1970.

Portantiero, Juan Carlos. "La múltiple transformación del Estado latinoamericano." Nueva Socicdad. Caracas, n. 104, 1989.

Prates, Antônio Augusto Pcrcira; ANDRADE, Luís Aurcliano Gama de. "Notas sobre o modelo de planejamento participativo: o caso de Minas Gerais. Revistu da Administraçio I'iblica. Rio de Janciro, vol. 19, n. 2, 1985.

Prats Y Catal Á, Joan. "Derecho y management en las administraciones públicas: notas sobre la crisis y renovación de los respectivos paradigmas." Reforma y Democracia: Revisıa del CI.AD, n. 3, 1995.

RABOTNIKOF, Nora. "Lo público e sus problemas: notas para una reconsideración." Revisıa Internacional de Filosofia Polifica. Madrid, n. 2, 1993.

RESTREPO BOTERo, Dario Indalecio. "Relaciones Estado-socicdad civil en el campo social: una reflexión desde el caso colombiano." Santafé de Bogotá: PARCOMUN. Mimeo, 1995.

Sánchliz Morón, Miguel. "Participación de la sociedad civil en programas sociales: el caso español." Madrid Universidad de Alcalá de Henares. Mimco, 1995.

StIf:FEl, Matthias; MARSH,LL, Wolfe. A voice for the exchuded: popular participation in developmenl: utopia or necessity? London: Zed Books, 1994.

Stuvers, Camilla. "The public agency as polis: active citizen." Admimistration and Society. Newbury Park, vol. 22, n. I, 1990.

Telles, Vera. "Sociedade civil c os caminhos (incertos) da cidadania." São Paulo, Universidade de São Paulo. Mimeo, 1994.

\section{Resumo}

Resúmen

Abstract

\section{A rearticulação das relaçōes Estado-socicdade: em busca de novos significados Nuria Cunill Cirou}

O presente artigo tem por objetivo examinar as novas formas de articulação das relaçōes entre o Estado e a sociedade propostas pelo pensamento político contemporänco. Partindo da constataçào de que existe uma tendencia à manutençào de uma abordagen instrumental destas relaçòes, sob um enfoque neoconservador, afirma-se que outros paradigmas podem ser buscados. Entretanto, o conteúdo das novas fórmulas propostas ainda najo estão fixados, ou são extremamente vagos, de modo que não contribuem necessariamente para conferir projeção diferente as relaçōes, nem atribuem novos sentidos a unia c a outra esfera.

\section{La rearticulacion de las relaciones Estado-Sociedad: en búsqueda de nuevos sentidos Nuriu Ciunill Grau}

El presente articulo tiene por objetivo examinar las nuevas formas propuestas por el pensamiento político contemporáneo de articulación de las relaciones entre el Estado y la Sociedad. En función de la constatación de que existe unás tendéncia a la manutención de un abordaje instrumental de estas relaciones, bajo un enfoque neoconservador, se afirma que otros paradigmas pueden ser buscados. Sin embargo, el contenido de las nuevas fórmulas propuestas todavia no están fijados o son extremamente vagos, de modo que no contribuyen necessariamente para conferir proyección diferente a las relaciones, ni atribuyen nuevos sentidos a una y a otra esfera.

The redesign of State-Society relations: in search of new meanings

Nuria Cunill Grau

The object of this article is to exam the new forms of the relations between State and Society as proposed by the contemporary political thought. The author first concludes that what prevails in the literature is a neo-conservative instrumental approach to the State-Society relations. She suggests that other approaches should be searched only to conclude that the new approaches proposed by contemporary authors are either too vague or have not yet been well defined. 